\title{
Servicios sociales y justicia restaurativa: el caso del Servicio de Mediación Penal de Barakaldo
}

\author{
Alberto José Olalde Altarejos \\ Facultad de Relaciones Laborales y Trabajo Social, Campus Araba, \\ Universidad del País Vasco (UPV-EHU) \\ <albertojose.olalde@ehu.eus>
}

\section{María Paz García-Longoria Serrano}

Facultad de Trabajo Social, Universidad de Murcia

\section{Gema Varona Martinez}

Instituto Vasco de Criminología-Kriminologiaren Euskal Institutua, Universidad del País Vasco (UPV-EHU)

\begin{abstract}
Justizia konponarazlearen etorrera Euskadiko epaitegietara errealitate handia eta oso aldakorra bihurtzen ari da, non zigor arloko justizia berritzen ari den. Biktimek ahotsa dute, ikertuak edo zigortuak diren pertsonek euren ekintzen ardura hartu ahal dute, eta biei diziplina ezberdinetatik datozen bitartekariak laguntzen ari zaizkie. Legea hautsi ondoren, konpondu beharreko ondorioetan oinarritzen da justizia konponarazlea, prozesu horretan elkarrekin nola erantzun eta etorkizunerako ondorioei partaideak aurre egiten saiatzen direlarik. Gizarte-eskuartze honek malgutasuna eta pertsonen beharretara egokitzea eskatzen du eta gizarte-zerbitzu zein osasun-zerbitzuen lankidetza beharrezkotzat jotzen da. Artikulu honetan lokarri honi ipiniko zaio arreta, eta Barakaldoko Zigor arloko zerbitzua eta beste zerbitzu hauen lokarria aztertuko da, 2007tik 2010ra doan epean. Lankidetza hau garatu zuen kasuak aztertu eta horren berezitasunei buruz hausnartuko da.
\end{abstract}

\section{GAKO-HITZAK:}

Justizia konponarazlea, bitartekaritza, gizartezerbitzuak, biktimak, gizarte eskuartzea.
La incorporación de la justicia restaurativa en los juzgados de Euskadi está suponiendo un giro copernicano en el sistema de justicia penal. Las víctimas tienen voz, las personas investigadas o condenadas pueden responsabilizarse de sus actos, y a ellas les asisten personas mediadoras profesionales, procedentes de diferentes disciplinas. La justicia restaurativa es entendida como el proceso a través del cual las personas afectadas por una infracción penal específica resuelven colectivamente cómo reaccionar tras ella y sus implicaciones para el futuro. La práctica de esta intervención social requiere, dada su flexibilidad y su orientación a las necesidades de las personas involucradas, la colaboración con otras instancias, como los servicios sociales o sociosanitarios. Este artículo reflexiona sobre esta conexión y estudia los vínculos existentes entre el Servicio de Mediación Penal de Barakaldo (Bizkaia) y esos servicios entre 2007 y 2010, analizando aquellos casos que requirieron de dicha colaboración y las peculiaridades de ésta.

\section{Palabras clave:}

Justicia restaurativa, mediación, servicios sociales, víctimas, intervención social. 


\section{Introducción}

En julio de 2007, de forma pionera nació en Euskadi el Servicio de Mediación Penal de Barakaldo (Bizkaia), en el marco del Departamento de Justicia del Gobierno Vasco. Muchas fueron las tensiones, críticas, recelos, oportunidades e ilusiones que se sentían con la instauración de novedosos y desconocidos procesos de justicia (restaurativa) en la justicia penal ordinaria. Los comienzos estuvieron llenos de novedades y sorpresas, dado que el sistema penal, caracterizado por la cultura del reproche, del castigo, de la privación de derechos, miraba de reojo a un sistema donde las personas implicadas (principalmente, víctimas y personas imputadas) se veían cara a cara para abordar de manera pacífica y colaborativa las consecuencias más humanas de sus conflictos de índole penal. El equipo de mediadores y mediadoras, en estrecha colaboración con el Departamento de Justicia, la Fiscalía y la jueza decana del Juzgado de Barakaldo, construyeron un camino nuevo en la justicia penal, que se ha convertido ya en un derecho de las víctimas. La tímida derivación durante el primer año, con escasos cincuenta conflictos penales, se multiplicó por diez en 2010. La apertura del servicio originó también la puesta en marcha de alianzas y colaboraciones con otros servicios, entre los que destacamos los servicios sociales. Este artículo pretende reflexionar sobre esta colaboración y las dificultades asociadas, a la luz del estudio de los 482 expedientes con proceso restaurativo durante el periodo 2007-2010.

\section{La justicia restaurativa}

Justicia restaurativa ${ }^{1}$, justicia reparadora (Tamarit, 2006), justicia participativa (Christie, 1984), justicia terapéutica (Wexler y Winick, 1996), justicia reconstructiva (Subijana, 2009), justicia restitutiva (Highton, Álvarez y Gregorio, 1998), justicia victimal (Beristain, 2006) o justicia recreadora (Beristain, 1995) son términos para una larga reivindicación, la recuperación del protagonismo de las víctimas²

${ }^{1}$ Este concepto fue promovido en el Congreso Internacional de Criminología celebrado en Budapest en 1993 (Manzanares, 2007). Se atribuye el término al psicólogo estadounidense Albert Eglash (1975), quien ponía de manifiesto los errores de la justicia penal: por un lado, negar a las víctimas una participación activa en el proceso penal; y por otro, maximizar una participación pasiva de las personas infractoras. Propuso la necesidad de que quien hubiera causado daño a otra persona se hiciera responsable de dicha conducta como medio y valor de rehabilitación (Bazemore, 2015; Walker, 2015).

2 Según la Declaración de las Naciones Unidas sobre los Principios Fundamentales de Justicia para las Víctimas de Delitos y del Abuso de Poder, de 29 de noviembre de 1985:

Art. 1. Se entenderá por 'víctimas' las personas que, individual o colectivamente, hayan sufrido daños, incluidas lesiones físicas o mentales, sufrimiento emocional, pérdida financiera o menoscabo sustancial de sus derechos fundamentales, como consecuencia de acciones u omisiones que violen la legislación penal vigente en los Estados Miembros, incluida la que proscribe el abuso de poder.

Art. 2. [...] En la expresión 'víctima', se incluye además, en su caso, a los familiares o dependientes inmediatos de la víctima di- en la resolución de los conflictos de índole penal ${ }^{3}$, sin olvidar al victimario y su contexto social. En esta variedad de conceptos alternativos, el de justicia restaurativa es "la solución más probada y que mejor soporta la crítica” (Tamarit, 2013: 140).

Durante las últimas décadas, la teoría sobre la justicia restaurativa ${ }^{4}$ y sus programas han resurgido, en parte para responder a la insatisfacción de las víctimas y su habitual frustración con el sistema de justicia tradicional. El paradigma retributivo, que tiende a enfatizar el castigo penal y la estigmatización, sigue teniendo fuerza en el ámbito de la jurisdicción penal. En esta visión de la justicia, el Estado se irroga el interés público y se define a sí mismo como la víctima. Toma un rol activo, para abordar el delito a través del castigo a la persona responsable y usa principalmente la pena privativa de libertad u otras formas de disuasión (Zehr, 2002). El paradigma restaurativo, en cambio, enfatiza el hecho de que la persona ofensora tiene responsabilidades que satisfacer hacia las personas a quienes ha dañado, no solamente acometiendo reparaciones -incluidas las simbólicas-, sino también reparando las relaciones deterioradas entre ella misma y la(s) víctima(s).

Reconociendo que el delito causa daños a las personas y comunidades, se insiste en que se reparen esos daños y que a las partes protagonistas de lo ocurrido se les permita participar en ese proceso. Los programas de justicia restaurativa, por consiguiente, habilitan a las víctimas, a la persona infractora y a los miembros afectados de la comunidad para que se involucren de forma directa en dar una respuesta al delito. Ellas llegan a ser el centro del proceso de esta justicia penal, con la ayuda de personas profesionales adecuadas, de un sistema que apunta a la responsabilidad de la persona infractora y a la reparación a las víctimas. El proceso restaurador debe involucrar a todas las partes, como aspecto fundamental para alcanzar el resultado restaurador de reparación y paz (Zehr, 2011).

recta, y a las personas que hayan sufrido daños al intervenir para asistir a la víctima en peligro o para prevenir la victimización.

Véase también la Directiva 2012/29/UE y su transposición a través de la Ley 4/2015 del Estatuto de la Víctima del Delito, donde se regulan expresamente los principios de la justicia restaurativa.

3 El ámbito de la resolución de conflictos es un espacio interdisciplinar, académico y profesional de teorización, investigación, formación y activismo que contiene el conjunto de conocimientos de todo tipo sobre el conflicto, incluyendo técnicas como la mediación, los métodos, estrategias y sistemas para su tratamiento y transformación positiva. Tradicionalmente, para referirse a los estudios de los conflictos se han utilizado los términos 'resolución', 'gestión' y ‘transformación'. El primero parece enfatizar la necesidad de alcanzar soluciones. El segundo refleja una percepción más positiva, introduciendo leyes, dinámicas o modelos para gestionarlos. Finalmente, el tercero tiene como fin la superación del conflicto mediante la reconciliación de las partes y la reconstrucción de las relaciones humanas (Paris, 2009).

4 "La justicia restaurativa es una forma de responder al comportamiento criminal equilibrando las necesidades de la comunidad, las víctimas y los delincuentes. Se trata de un concepto en evolución, que ha dado lugar a diferentes interpretaciones en diferentes países, y en torno al cual no existe el consenso perfecto. Ello se debe, en parte, a las dificultades para traducir con precisión el concepto en diferentes idiomas, y a la variada terminología que a menudo se utiliza" (Oficina de las Naciones Unidas para la Droga y el Delito, 2006: 6). 
Las diferencias con la justicia retributiva son un modo habitual de comprender la esencia de este tipo de justicia:

- Ve los hechos delictivos de forma más amplia: en vez de defender el delito como mera trasgresión de las leyes, reconoce que las personas infractoras dañan a las víctimas, las comunidades y se dañan a ellas mismas.

- Involucra a más personas en la respuesta al delito. En lugar de dar el papel clave al Estado y a la persona infractora, a esta última le permite desarrollar su responsabilidad activa, incluida la participación de la víctima y otras personas afectadas de la comunidad.

- Mide de forma diferente el éxito: en vez de medir cuánto castigo debe imponerse, mide cuántos daños deben ser repararse o prevenirse.

Desde las primeras prácticas reconocidas de justicia restaurativa, en 1974, encontramos una prolífica literatura que intenta explicarlas y darles fundamento teórico, constatando que, dentro de este amplio paradigma conceptual, hay muchas formas de entenderla5. A continuación, destacamos dos acepciones con reconocimiento internacional:

La justicia restaurativa es un proceso a través del cual las personas afectadas por una infracción específica resuelven colectivamente cómo reaccionar tras aquella y sus implicaciones para el futuro (Marshall, 1999: 5).

[Es] un proceso donde todas las personas con algún interés afectadas por una injusticia tienen la oportunidad de discutir las consecuencias de la injusticia y lo que se podría hacer para poner las cosas en su lugar. El valor clave es que, dado que la injusticia daña, la justicia debe sanar (Braithwaite, 2003: 35).

Es necesario hacer una distinción en el sentido que la justicia restaurativa se sitúa en torno a la injusticia y no se muestra moralmente neutra acerca de ella. La injusticia se define en términos de dominación, por lo que se siente como algo que está mal. Por ello, la justicia restaurativa es una filosofía que rechaza la neutralidad moral de la mediación que define todo en términos de lenguaje moralmente neutral de conflicto (Braithwaite, 2003) $^{6}$.

5 Ésa es la fecha histórica reconocida internacionalmente en la literatura especializada como el momento del nacimiento de la justicia restaurativa en Canadá, concretamente en la ciudad de Elmira (Ontario), cuando el agente de libertad condicional Mark Yantzi sugirió por primera vez al juez un proceso restaurativo. Dos jóvenes de la ciudad fueron declarados culpables de veintidós cargos por daños intencionales, a raíz de una noche de sábado de prácticas vandálicas y conducción bajo los efectos del alcohol. A pesar de la sorpresa del juez, éste aceptó que los jóvenes se responsabilizaran de las pérdidas económicas ocasionadas y se encontraran con sus víctimas, con la asistencia de Dave Worth y Mark Yantzi. Como consecuencia de ello, los dos jóvenes visitaron y hablaron con todas las víctimas (Larson y Zehr, 2007).

${ }^{6}$ De hecho, esta tendencia a mirar al conflicto con lentes de neutralidad y de mediación puede provocar un efecto perverso, al asociar
Hoy día, la justicia restaurativa es considerada un movimiento internacional, que va alcanzando mayor apoyo entre los Gobiernos, las y los profesionales de la justicia penal, los grupos de apoyo a las víctimas, los jueces y las juezas, y las fuerzas de seguridad, quienes reconocen que el sistema de justicia penal -enfocado principalmente a la persona ofensorano funciona (Wright, 1991; Bazemore y Umbreit, 1995; Umbreit et al., 2005; Van Wormer, 2008; Van Ness y Strong, 2010). El foco de la justicia restaurativa, en cambio, está en la persona ofensora, la víctima y la comunidad afectada.

\subsection{La colaboración entre los programas de justicia restaurativa y los servicios sociales}

Los programas de justicia restaurativa habitualmente se ponen en marcha en el contexto de la administración de justicia penal. Una mirada histórica a su implantación en España nos muestra los primeros programas piloto intrajudiciales de Valencia (1993), Barcelona (1998) y Vitoria-Gasteiz (1998), con equipos multidisciplinares. Frente a esta forma de institucionalización, se sitúa un programa de mediación penal comunitaria de la Asociación Apoyo (1999), asentado sobre la base de voluntariado y que supera el modelo de mediación intrajudicial anterior. A este respecto, Segovia Bernabé (2010: 21) señala:

La mediación penal comunitaria no es, no puede ser, una mera herramienta más al servicio de la justicia penal convencional. Obliga a una recolocación crítica de todo el sistema, de los operadores jurídicos y de todos los actores sociales. En este horizonte, no cabe apostar por un único modelo de mediación intrajudicial. Más bien, la Justicia Restaurativa exige cuidar y cultivar el extrajudicial y comunitario (si bien sus resultas acaban incorporadas al proceso penal y es tutelado por el Ministerio Fiscal).

Nuestra perspectiva quiere mirar a la colaboración y el trabajo en red entre los programas de justicia restaurativa que se vayan poniendo en marcha, 0 ya lo estén, y los servicios sociales más cercanos a ellos.

La cercanía a la ciudadanía permite recuperar su protagonismo sin poner en marcha toda la maquinaria penal, dado que la administración de justicia penal se encuentra a menudo perdida y agobiada cuando debe resolver conflictos donde las familias, las escuelas, los vecinos y las vecinas se han visto sobrepasadas para controlarlos dentro de sus límites (Peters y Aertsen, 1995).

este tipo de mediación con la negociación de los conflictos y confundir a la sociedad. El delito no es negociable, por lo que el objetivo es el diálogo. Por ello, la mediación víctima-ofensor puede verse como un término equivocado, por hacer sólo referencia al espacio privado entre persona víctima y ofensora (Cutrona, 2014). Este paradigma de justicia promueve un sentido comunitario de justicia, de construcción de paz, cediendo la voz a la comunidad y la víctima a la hora de res. ponder a las consecuencias del delito. 
El ámbito de la justicia juvenil ha sido quizás el que ha podido desarrollar más estas colaboraciones, llegando incluso a facilitar los procesos restaurativos en la propia sede de los servicios sociales. En este sentido, destaca la experiencia del Programa de Prevención y Mediación Comunitaria, que da respuesta en la comunidad a las dinámicas conflictivas protagonizadas por jóvenes, a través de actuaciones encaminadas a reforzar la capacidad de los ayuntamientos, instituciones y profesionales que operan en la comunidad, con el objetivo final de desarrollar políticas y programas de prevención con perspectiva de justicia restaurativa. El programa consigue abordar la descoordinación entre los servicios de justicia juvenil y los servicios sociales, que provocaba que las intervenciones se dilataran en el tiempo (Nogueras y Gimeno, 2015).

La perspectiva de justicia restaurativa en el ámbito juvenil ha primado principalmente el interés educativo de las medidas para los y las menores infractoras, proponiendo que este contenido educativo "ayude al joven, en su proceso de aprendizaje y de maduración, a que entienda la realidad que le rodea y a darle elementos para que sea capaz de desenvolverse dentro de la sociedad en la que se encuentra" (Nogueras y Gimeno, 2012: 5). En este sentido, quizás la víctima ha podido ser vista como un instrumento para ese proceso educativo. Desde un punto de vista metodológico, el proceso de justicia restaurativa en el ámbito juvenil busca, en la fase de contacto, mostrar una actitud de escucha y valoración del grado de victimización (Álvarez Ramos, 2008).

En el contexto internacional, la justicia juvenil ha mostrado una sensibilidad y coordinación mayor con los servicios sociales ${ }^{7}$. La Oficina de las Naciones Unidas para la Droga y el Delito, en su documento sobre justicia restaurativa para niños y niñas (2013), incorpora la formación de profesionales de servicios sociales para la facilitación de círculos ${ }^{8}$. En Nueva Zelanda, las conferencias ${ }^{9}$ familiares son habitualmente facilitadas por un o una trabajadora social (youth Justice coordinator) [Macrae y Zehr, 2004]. En este tipo de prácticas de justicia restaurativa en Australia, la trabajadora social puede explicar el contexto del consumo de drogas por parte del menor o de la menor. En Bélgica, igualmente se integraba en la

7 Destaca el modelo finlandés, donde las personas mediadoras, voluntarias, desarrollan su labor en los servicios sociales (Dünkel, Horsfield y Păroşanu, 2015). El Observatorio Internacional de Justicia Juvenil recomienda la implementación de protocolos de colaboración y relación profesional positiva entre los juzgados, las escuelas y los servicios sociales (Chapman, Gellin y Anderson, 2015).

${ }^{8}$ Los círculos, inicialmente también llamados sentencias circulares, fueron diseñados para desarrollar un amplio consenso entre miembros de la comunidad afectada por los hechos delictivos, las víctimas, defensores/as de éstas, las personas ofensoras, jueces y juezas, miembros de la Fiscalía, Consejos de Defensa, Policía y trabajadores y trabajadoras de la administración de Justicia (Bazemore y Umbreit, 1999).

9 La conferencia es un proceso donde un grupo de personas conectadas y afectadas por una acción pasada se juntan a discutir sobre los problemas creados. Es similar a la mediación en el sentido de que pone juntos a persona ofensora y víctima, pero incluye también a otras personas afectadas. Dado que es un proceso grupal, la dinámica de la conferencia es muy diferente del diálogo mediado (McCold, 2000). implementación de los proyectos piloto de conferencia a los servicios sociales (Guardiola et al., 2012). El Foro Europeo de Justicia Restaurativa promovió en 2008 el proyecto 'Conferencing: Away for Restorative Justice in Europe', donde pueden conocerse experiencias europeas de implementación de programas de este tipo desde los servicios sociales (Zinsstag, Teunkens y Pali, 2011).

En el ámbito de los delitos graves cometidos por jóvenes, el proyecto piloto de Flandes (Bélgica) colabora con los servicios sociales de los juzgados de menores, los cuales valoran la situación personal y social (familia, relaciones, drogas) para llevar a cabo una conferencia, y realizar posteriormente el seguimiento del resultado restaurativo (Vanfraechem, 2003).

\section{El Servicio de Mediación Penal de Barakaldo}

El Servicio de Mediación Penal de Barakaldo nació en julio de 2007, tras las oportunas conversaciones y negociaciones entre los siguientes agentes: $D^{\underline{a}}$ Cristina de Vicente, jueza decana de Barakaldo y jueza del Juzgado de lo Penal no 2; Dạ Maria Ángeles Montes, fiscal jefe de la Comunidad Autónoma del País Vasco; D. Xabier Karlos Etxebarria, director de Ejecución Penal del Departamento de Justicia, Empleo y Seguridad Social del Gobierno Vasco; y por último, D. Félix Pantoja García, vocal del Consejo General del Poder Judicial.

El Departamento de Justicia del Gobierno Vasco fue el encargado del diseño e impulso económico del servicio, recayendo la gestión, a través de un convenio de colaboración, en un equipo de mediación profesional de GEUZ-Centro Universitario de Transformación de Conflictos ${ }^{10}$. El novedoso servicio nacía con dudas y reticencias por parte tanto del propio juzgado como de la Fiscalía, tal y como señalaba la propia jueza decana (De Vicente, 2007: 8):

No escondemos que la propuesta suscitó simultáneamente curiosidad y escepticismo. No sabíamos qué era la mediación, pero nos parecía que tenía cierto componente ideológico que nos suscitaba un inicial recelo. No sabíamos para qué servía la mediación, pero nos parecía que no podía servir para mucho o que sus finalidades quedarían reducidas a un pequeño grupo de asuntos de escasa relevancia penal. También debíamos superar obstáculos conceptuales: en general, a los juristas el conflicto que subyace al delito no nos importa, a veces nos incomoda y las más de las veces lo eludimos, porque nos hace perder un tiempo del que no disponemos. Nuestro

${ }^{10}$ El 1 de enero de 2011, el Servicio de Mediación Penal pasó a denominarse Servicio de Mediación Intrajudicial de Bizkaia, ampliando su ámbito de intervención a todos los partidos judiciales de este territorio, y su objeto de intervención, a la jurisdicción civil familiar. La gestión fue encomendada a la Asociación Adosten. 
foco de atención está puesto en el delito, y no en las causas que lo motivan.

Para la Fiscalía, el servicio también suponía recelos, dado que nuestro sistema jurídico parecía bastante alejado ante el nuevo reto de la mediación en el ámbito penal, “y no porque me pareciera un sistema equivocado, peligroso incluso para los fines que se pretendían, sino porque, desde el punto de vista de la Fiscalía, lo consideraba inaplicable y en abierta confrontación con el principio de legalidad penal” (Montes, 2007: 2).

El sistema de justicia penal se veía confrontado, pues, por una nueva lógica, aquella que trae la humanización de los conflictos de índole penal, la que da la oportunidad al encuentro que repara el daño sufrido por la víctima y permite procesos de responsabilización de la persona ofensora. El Servicio de Mediación Penal de Barakaldo se dotó de un protocolo de funcionamiento abierto y dinámico, que supuso la aceptación por parte del sistema penal de esta nueva vía de intervención social y criminológica. La opinión favorable de la Fiscalía se constataba en la evaluación externa del propio servicio, donde se señalaba el valor positivo de lograr una comunicación eficaz entre personas vinculadas por hechos delictivos, que contribuye a evitar a las personas participantes futuros conflictos (Varona, 2009).

El servicio fue creciendo paulatinamente, tanto en respeto y valoración positiva como en volumen de derivación: 28 expedientes en 2007, 203 en 2008, 290 en 2009 y 282 en 2010 . En total, fueron remitidos 803 expedientes, llegando a existir proceso restaurativo en el $64 \%$ de las derivaciones. Las personas participantes alcanzaron acuerdos en el $82 \%$ de los procesos, con una intervención de menos de dos meses en el $70 \%$ de los casos. Se atendió a un total de 1.961 personas.

La mediación directa supone un 50,4\%, y la indirecta (aquella donde las personas protagonistas no se ven directamente cara a cara), un 40,5\%. En el 7,1\% de casos, habiendo empezado como mediación directa, las personas decidieron continuar o acabar de manera indirecta, es decir, sin verse cara a cara. El proceso restaurativo por medio de conferencia supuso un $1,7 \%$ del total, y en estos casos, además de las víctimas y las personas ofensoras, participaron también personas en calidad de afectadas por los hechos ocurridos (por orden de importancia, familiares, vecinos/as y profesionales de trabajo social). Por último, en un $0,5 \%$ de casos se realizó por videoconferencia desde la prisión donde residía el victimario.

Las personas participantes construyen acuerdos restaurativos que dan respuestas a sus necesidades, que permiten la reparación a las víctimas y aportan los compromisos de responsabilización de las personas imputadas. La Tabla 1 muestra en qué consisten dichos acuerdos.

La evolución de la derivación fue un proceso en crecimiento, que supuso la confirmación de la confianza, o quizás curiosidad, con la que actuaba el sistema de justicia penal derivando expedientes. En el Gráfico 1, podemos observar la evolución de la derivación según las tipologías delictivas de delito y falta, de acuerdo con la legislación del momento ${ }^{11}$.

Tabla 1. Frecuencia y porcentaje de los contenidos de los acuerdos. Servicio de Mediación Penal de Barakaldo, 2007-2010 $(\mathrm{N}=395)$

\begin{tabular}{|c|c|c|}
\hline & \\
\hline & $f$ & $\%$ \\
\hline Renuncia a acciones civiles y penales & 361 & 91,39 \\
\hline Disculpas formales & 262 & 66,33 \\
\hline Compromiso de que los hechos no vuelvan a ocurrir & 237 & 60,00 \\
\hline Respeto mutuo & 167 & 42,28 \\
\hline Pago a la víctima & 106 & 26,84 \\
\hline Tratamiento psicosocial & 66 & 16,71 \\
\hline Compromiso por el diálogo & 59 & 14,94 \\
\hline Realización de trabajos de reflexión por escrito & 19 & 4,81 \\
\hline Servicios comunitarios & 14 & 3,54 \\
\hline Retirada de la denuncia & 11 & 2,78 \\
\hline Donación de dinero o bienes a instituciones benéficas & 2 & 0,51 \\
\hline
\end{tabular}

Fuente: Olalde (2015).

${ }^{11}$ La Ley Orgánica 1/2015, de 30 de marzo, en su disposición derogatoria, declara derogado "el Libro III de la Ley Orgánica 10/1995, de 23 de noviembre, del Código Penal”, es decir, el libro de las faltas y sus penas. Por su parte, en su artículo 9 dispone la modificación del art. 13.3 del Código Penal ("son faltas las infracciones que la Ley castiga con pena leve"), que desde el 1 de julio de 2015 tiene la siguiente redacción: "son delitos leves las infracciones que la ley castiga con pena leve”. Ténganse en cuenta las posibilidades que se abren con un cierto principio de oportunidad reglada respecto de la modificación, en 2015 de la Ley de Enjuiciamiento Criminal, donde se alude a la mediación. 
Los dos primeros años, las infracciones graves superaban a las leves, a la inversa de lo que ocurre en los actuales servicios de mediación intrajudicial de Euskadi ${ }^{12}$.

En este Gráfico 2, podemos observar la desigual derivación de los diferentes Juzgados del partido judicial de Barakaldo durante el periodo 2007-2010.

\section{El Protocolo abierto y dinámico}

El contexto normativo sobre el que se construye la práctica de la mediación en el Servicio de Mediación Penal de Barakaldo es el llamado Protocolo abierto y dinámico de mediación penal reparadora de la Comunidad Autónoma del País Vasco. A grandes rasgos, el protocolo contiene:

- Los delitos y faltas susceptibles de mediación.

- Las posibles repercusiones penales de la mediación.

- Los criterios de derivación por parte del Juzgado o secretario/a judicial en la fase de instrucción, enjuiciamiento o ejecución, tanto para faltas como para delitos.

- El procedimiento de inicio de la actuación.

- Las fases del proceso de mediación.

- La decisión judicial.

- El seguimiento de la reparación.

Gráfico 1. Evolución anual de la derivación según tipos de infracción. Servicio de Mediación Penal de Barakaldo, 2007-2010

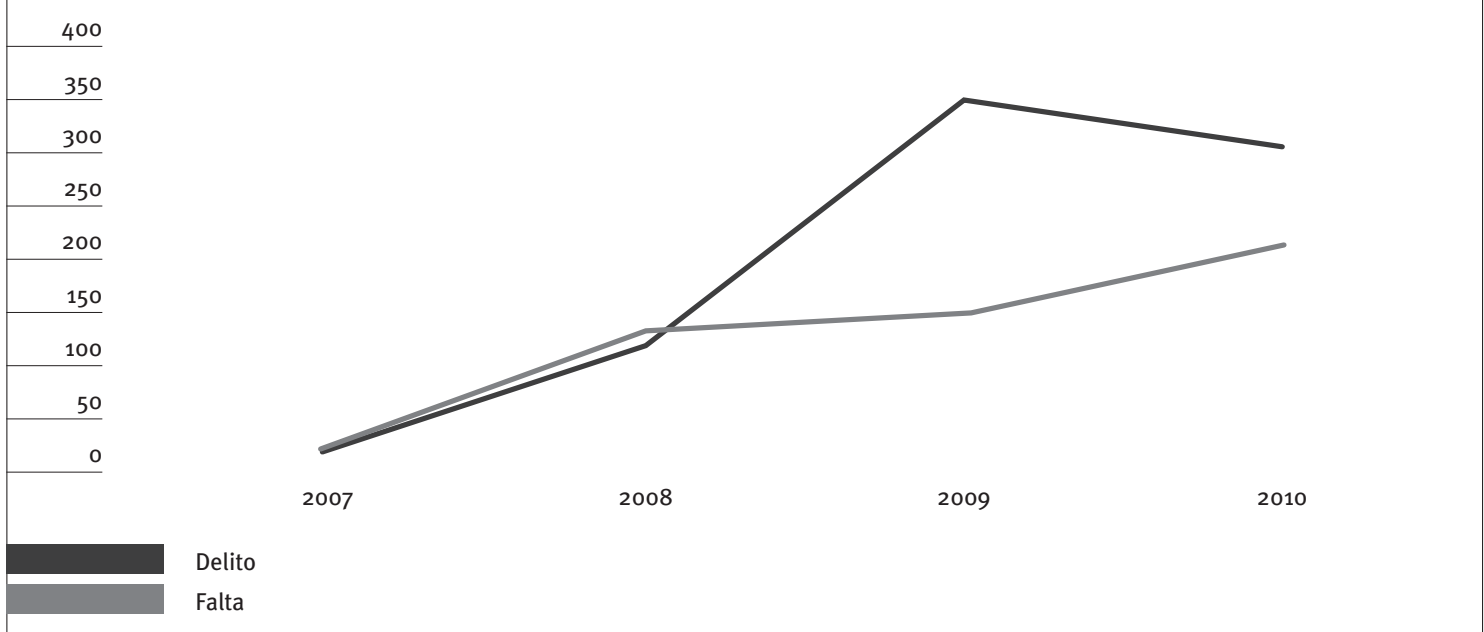

Fuente: Olalde (2015).

Gráfico 2. Evolución de la derivación según juzgados. Servicio de Mediación Penal de Barakaldo, 2007-2010
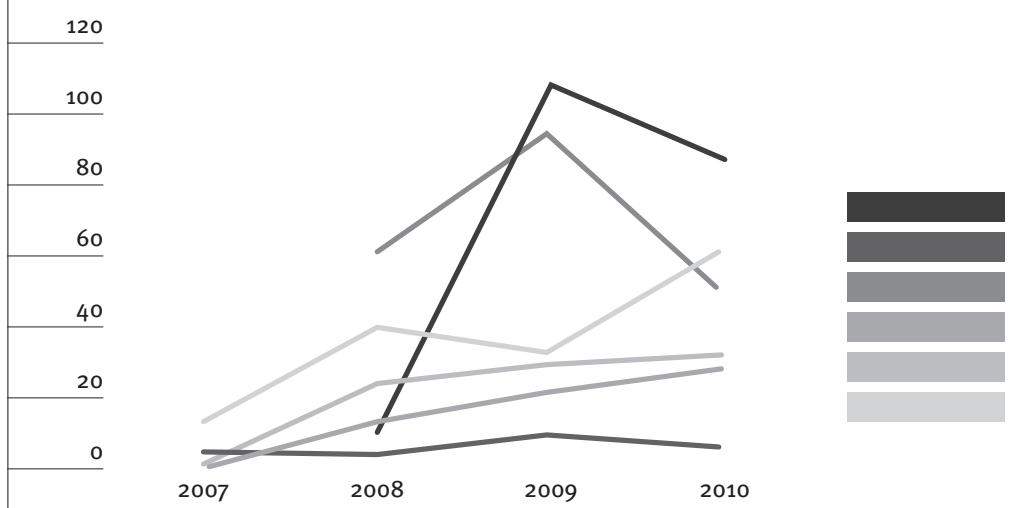

Juzgado de Instrucción $n^{0}{ }_{1}$ Juzgado de Instrucción no 2 Juzgado de Instrucción $\mathrm{n} \div 3$ Juzgado de Instrucción nํㅜ 4 Juzgado de lo Penal no 1 Juzgado de lo Penal $n \underline{0} 2$

Fuente: Olalde (2015).

${ }^{12}$ Véanse las memorias del Servicio de Mediación Intrajudicial de Euskadi de 2014 y 2015 (Departamento de Administración Pública y Justicia, 2015, 2016). En 2014, los delitos derivados fueron un $15 \%$, frente a $85 \%$ de faltas. En 2015 , los delitos alcanzaron un $64 \%$, y las faltas, un $36 \%$. 
Este protocolo fue revisado periódicamente por la Dirección de Ejecución Penal, el Ministerio Fiscal, el Juzgado Decano y el propio Servicio de Mediación Penal, siendo un instrumento que daba cobertura y seguridad jurídica a la relación del servicio con el órgano derivador. El carácter dinámico y abierto del protocolo permitió que las partes implicadas construyeran con flexibilidad una práctica basada en el respeto a las garantías jurídicas y a la flexibilidad. Dicho documento sigue siendo, con escasas modificaciones ${ }^{13}$, el instrumento legal sobre el que se apoyan actualmente los servicios de mediación intrajudicial de Euskadi. En este sentido, la ausencia de normativa legal "provoca que la derivación de casos penales a los Servicios de Mediación se realice a través protocolos que carecen del valor jurídico predicable de una ley o norma reguladora general [...]. Esta situación, a mi juicio, es difícilmente conciliable con valores constitucionales como la seguridad jurídica y la igualdad de todos los ciudadanos en el acceso a las prestaciones jurisdiccionales a la que tiene derecho" (Subijana, 2014: 366).

De acuerdo con el convenio firmado por GEUZ y el Departamento de Justicia del Gobierno Vasco, el equipo de justicia restaurativa debe:

- Proporcionar los medios personales y materiales necesarios para la correcta realización del servicio. Las exigencias mínimas del Departamento en este apartado son las siguientes:

- Un/a licenciado/a, un/a diplomado/a y un/a auxiliar administrativo/ $\mathrm{a}^{14}$, todos ellos con formación reglada específica en mediación.

- Para poder actuar como persona mediadora, será preciso acreditar licenciatura en Derecho, Psicología, Pedagogía, Psicopedagogía o diplomatura en Trabajo Social o en Educación Social, o aquella titulación que se equipare a ellas por el contenido de su formación. Además, será imprescindible demostrar una preparación específica, suficiente y continua en mediación.

- La persona mediadora tiene derecho a obtener el adecuado respeto a sus actuaciones, y a actuar con libertad e independencia en el ejercicio de su actividad.

- Si lo estimara conveniente, la persona mediadora podrá proponer, en calidad de consultoras, la presencia de otras personas que tengan relación con la causa u objeto de la mediación, debiendo someter esta participación a la previa aceptación de las partes.

- La persona mediadora, a lo largo de su actuación, debe:

${ }^{13}$ Véase el actual protocolo, disponible en 〈http://www.justizia. net/mediacion-intrajudicial/documentos〉.

${ }_{14}$ La asociación GEUZ optó por ausentar la figura de auxiliar administrativo y enriquecer el equipo con personas tituladas en Derecho, Psicología y Trabajo Social, que compartían las tareas administrativas.
- Respetar los principios rectores de la mediación.

- Utilizar el procedimiento de mediación como vía para que las partes adopten soluciones aceptables.

- Facilitar la comunicación entre las partes.

- Propiciar que las partes dispongan de la información y el asesoramiento suficiente para alcanzar los acuerdos de forma libre, voluntaria y exenta de coacciones.

- Incompatibilidades:

- La persona mediadora no podrá ejercer como tal cuando tenga vínculos de parentesco por consanguinidad o afinidad hasta el cuarto grado con alguna de las partes, exista amistad íntima o enemistad manifiesta con las partes sometidas a mediación, haya conocido ese conflicto como consecuencia del ejercicio de su profesión de origen o los intereses que se manejan sean contrapuestos a otros en los que esté interviniendo.

- Durante el transcurso de la mediación, o una vez finalizada ésta, la persona mediadora no podrá atender a las partes en una actuación profesional diferente a la de mediación para tratar el mismo asunto, salvo que las partes expresamente lo acepten y constituyan supuestos excepcionales, que deberán ser autorizados por el Departamento del Gobierno Vasco competente en materia de mediación penal.

\section{El marco de intervención}

El proyecto de intervención del servicio desarrolla su diseño, organización, puesta en funcionamiento, seguimiento y evaluación siguiendo el Protocolo abierto y dinámico de mediación penal reparadora en la Comunidad Autónoma del País Vasco, en el partido judicial de Barakaldo (Olalde, Romera y Agirre, 2007). Su objetivo general es:

Ofrecer un sistema de mediación en las distintas fases del proceso penal -instrucción, enjuiciamiento y ejecución-, de cara a que tanto la persona que ha sufrido el delito como la que es denunciada, voluntaria y confidencialmente, y dentro del proceso penal, cuenten con la posibilidad de participar activamente en la resolución o transformación del conflicto delictivo en el que están implicadas, profundizando en la comunicación, el diálogo constructivo y la toma de acuerdos consensuados que busquen la fórmula más idónea para satisfacer las necesidades personales y sociales de ambas partes, con la facilitación o asistencia de una/s persona/s mediadora/s (ibídem: 25).

Como objetivos específicos, figuran:

- Desarrollar un modelo de mediación en el ámbito penal que favorezca la toma de decisiones de 
las partes en relación con el hecho cometido, de forma consensuada y responsable.

- Consolidar, junto con los operadores jurídicos involucrados de los juzgados de instrucción y de lo penal del partido judicial de Barakaldo, una metodología de solución colaborativa para el abordaje de determinados conflictos penales.

- Enriquecer el proceso resolutivo del conflicto, mediante la comunicación entre las partes y la introducción por ellas de aspectos subjetivos que suelen quedar al margen del procedimiento penal formal, lo que consigue una mayor profundidad en la solución consensuada respeto a la mera sanción penal.

- Promover la responsabilización y la reparación del daño producido por la persona acusada de haber cometido una infracción penal.

- Dotar de protagonismo a la víctima en la resolución y trasformación del conflicto que le atañe.

- Dotar a la persona víctima de una acción penal de un espacio seguro en el que poder expresar sus sentimientos y necesidades.

- Ofrecer a la víctima una reparación real en relación con el daño sufrido en la acción penal.

- Aportar una mayor comprensibilidad a todo el proceso para ambas partes.

- Realizar una evaluación interna y externa del Servicio en aras de su mejora continua.

- Contribuir a la difusión y sensibilización de la mediación en la sociedad vasca como método eficaz para resolver conflictos en el ámbito penal de un modo dialogante y consensuado.

- Contribuir a la agilización de los procedimientos judiciales, disminuir la carga de trabajo de la administración de Justicia y favorecer la descongestión del sistema penal. En la medida en que todo el proceso se realiza controlado por los operadores jurídicos -y en última instancia, el acuerdo entre las partes requiere la sanción judicial-, se garantizan los derechos de todas las partes, así como el interés público inmanente al ius puniendi.

- Realizar un trabajo en red con los diferentes servicios de cooperación con la Justicia dependientes de la Dirección de Ejecución Penal del Gobierno Vasco. Trabajar en red con otras organizaciones y servicios sociales del partido judicial de Barakaldo.

- Colaborar en la creación de una cultura social de paz, integradora y tolerante.

Durante el periodo de estudio, se realizaron dos evaluaciones externas. En la primera, se constataron los siguientes hallazgos (Varona, 2008):

- El positivo grado de satisfacción de las víctimas y las personas ofensoras participantes.

- Que los efectos positivos del servicio superaban los posibles efectos negativos.

- La dinámica positiva de las personas mediadoras percibida por las personas participantes.
- Un modelo teórico integrado y con lógica de trabajo en red.

- El volumen aceptable y la entidad (incluidos casos graves) de los casos mediados.

- Los beneficios para la administración de Justicia, las personas participantes y la propia comunidad.

La segunda evaluación, que abarcó, además del de Barakaldo, los servicios de mediación penal de Bilbao, Vitoria-Gasteiz y Donostia-San Sebastián, pretendió evaluar el impacto de dichos servicios y, más específicamente, la valoración de estos tres aspectos (Varona, 2009):

- La disminución de la victimización, en su acepción extensa.

- La minoración de la estigmatización de las personas denunciadas.

- La satisfacción general de las partes implicadas, en un sentido amplio, así como de los operadores jurídicos, respecto de los resultados y del propio proceso mediador y reparador, inmersos en su contexto sociojurídico.

Los resultados de esta evaluación fueron positivos y se constata el cumplimiento de los objetivos del Servicio de Mediación Penal de Barakaldo ${ }^{15}$. Igualmente, se observa que este tipo de programas son una innovación social que contribuye a la calidad de administración de Justicia. Así, el programa comparte características de la democracia deliberativa y puede contribuir al desarrollo de capital humano (Varona, 2009).

Por último, de cara a comprender la idiosincrasia de esta intervención restaurativa, queremos hacer referencia a otra investigación realizada a partir de las evaluaciones externas llevadas a cabo en Euskadi, que propone unidades de análisis para la identificación de factores inhibidores y facilitadores de los programas de justicia restaurativa tanto en la jurisdicción de menores como en la de personas adultas. En ese sentido, el póster científico de dicha investigación aborda los contextos favorecedores de estos programas, constatando que están relacionados con capacidades y contextos asociados con competencias de adaptabilidad, vínculo social, empatía, asertividad, resolución, tenacidad y creatividad. Igualmente, se destaca la importancia de favorecer contextos para soluciones inesperadas, que manejen niveles aceptables de incertidumbre. Se trata, no tanto de controlar la incertidumbre, sino de sacar partido de sus aspectos positivos, desde la conciencia de su irreductibilidad (Varona, Igartua y Olalde, 2011) ${ }^{16}$.

${ }^{15}$ Véanse igualmente los resultados de la investigación sobre el coste de la justicia restaurativa en la sede de Araba del Servicio de Mediación Intrajudicial de Euskadi, donde se constata que, para el $59 \%$ de las personas entrevistadas, la mediación ha aportado técnicas o consejos útiles en el manejo de conflictos personales. Igualmente reseñable es el hecho de que la actuación de las personas mediadoras sea lo que recuerden como más positivo el $41 \%$ de los casos (Igartua et al., 2015).

${ }^{16}$ En esta línea, una reciente investigación realizada en los Servicios de Mediación Intrajudicial de Euskadi (Delegación de Araba) de- 


\section{Análisis de datos}

Visto el contexto de nuestro estudio, nuestra tarea investigadora se ha realizado a partir de la identificación de los datos presentes en la base de datos del Servicio de Mediación Penal de Barakaldo, recogidos por el equipo de mediadores y mediadoras y analizados por este investigador e investigadoras. Se ha examinado la información cualitativa relacionada con el servicio con el cual se ha establecido conexión (durante el proceso restaurativo) o derivación (después del proceso restaurativo). También se han estudiado referencias directas a servicios sociales que muestran las cláusulas de los 395 acuerdos construidos por las personas participantes.

\subsection{Conexión y derivación a otros servicios sociales}

Durante el periodo de estudio, en el que se culminaron 482 procesos restaurativos, hubo 46 que requirieron de colaboración de otros servicios sociales, sociosanitarios y de cooperación con la Justicia, y supusieron un 9,5\% del total. La Tabla 2 nos ilustra dónde fueron derivados esos 46 expedientes, destacando un $24,4 \%$ que fueron derivados al servicio público de mediación familiar; un $22,2 \%$ a asociaciones de personas afectadas; y un $17,8 \%$, a servicios de salud mental ${ }^{17}$. La derivación de casos a mediación familiar está relacionada con los expedientes judiciales con faltas de incumplimiento de régimen de visitas (14,75\% de los casos) y la mayor idoneidad para continuar el proceso en un contexto de trabajo de mediación familiar.

Tabla 2. Frecuencias y porcentajes de los servicios sociales derivados

\begin{tabular}{|l|c|c|}
\cline { 2 - 3 } \multicolumn{1}{c|}{} & $f$ & $\%$ \\
\hline Servicio público de mediación familiar & 11 & 24,4 \\
\hline Asociaciones de personas afectadas & 10 & 22,2 \\
\hline Salud mental & 8 & 17,8 \\
\hline Servicio de Asistencia a la Ejecución (SAER) & 7 & 15,6 \\
\hline Servicio de Atención a la Víctima (SAV) & 5 & 11,1 \\
\hline Servicios sociales de atención primaria & 4 & 8,9 \\
\hline Servicio de Atención al Detenido/a (SAOS) & 1 & 2,2 \\
\hline Total & 46 & 100,0 \\
\hline
\end{tabular}

Fuente: Olalde (2015).

muestra que los programas de justicia restaurativa ponen en valor el dialogo social, la adquisición de herramientas o técnicas útiles para manejar conflictos interpersonales, la alta valoración de los y las profesionales de justicia restaurativa (que buscan la empatía mutua) y el éxito en la obtención de acuerdos (Igartua et al., 2015).

${ }^{17}$ Véase, en ese sentido, su relación con aspectos de la justicia terapéutica que "propone y articula respuestas rehabilitadoras para las personas condenadas por ilícitos penales que presentan riesgos criminógenos vinculados, fundamentalmente, a la presencia de patologías mentales, a adicciones, al consumo de bebidas alcohólicas, drogas tóxicas o estupefacientes, y a alteraciones conductuales por distorsiones cognitivas o deficiencias emocionales" (Subijana y Porres, 2013: 22).

\subsection{Referencias a servicios sociales en cláusulas de} acuerdos

A continuación, y a modo de ejemplo, destacamos párrafos entresacados de acuerdos que hacen referencia tanto a tratamientos o intervenciones de carácter psicosocial como a derivación o continuación de la intervención social con servicios sociales ${ }^{18}$ :

Segundo. D. [...] se compromete a no reincidir en este tipo de comportamientos, para lo cual reitera su compromiso de continuar el tratamiento de deshabituación de tóxicos iniciado en el Centro de Salud Mental de [...] y que continuará, previa gestión desde los Servicios Sociales de [...] en coordinación con el Centro referido, en comunidad terapéutica privada, en el Centro Terapéutico de [...], sito en la provincia de [...], gestionado por la Asociación [...], con fecha de ingreso prevista para la primera semana de marzo y una duración aproximada de tratamiento de seis a nueve meses.

En este sentido, Dña. [...] se compromete a solicitar, en el plazo máximo de una semana, intervención socioeducativa en los Servicios Sociales de Base de [...], con los que actualmente se encuentra en contacto, reafirmándose en su compromiso de iniciar y colaborar con las propuestas que, desde el programa de intervención social del Ayuntamiento de [...] se realicen en relación con su unidad familiar, en aras a poner en práctica nuevas herramientas y pautas educativas que le ayuden en la crianza de sus hijos.

En la fase de la reunión en que cada miembro de la familia expone lo que cada uno necesita para lograr un mayor bienestar, los padres explican que estarían muy agradecidos si consiguieran apoyo psicológico para sus dos hijas menores, [...] y [...], por las consecuencias que pueden tener en su desarrollo madurativo determinadas experiencias traumáticas que vivieron en los años en que ellos no estuvieron presentes, por lo que harán una solicitud explícita a los Servicios Sociales del Ayuntamiento de [...], de quienes ya están recibiendo apoyo social y familiar.

Tercero. De cara a poder atender las necesidades de Dña. [...], ambos manifiestan estar en contacto con los servicios sociales de [...] al objeto de solicitar la valoración del grado de dependencia de Dña. [...] y su ingreso en centro residencial para personas mayores, información ésta contrastada desde este servicio con los servicios sociales aludidos, desde donde refieren estar tramitando y gestionando la petición cursada.

Don [...] se compromete a acudir al programa de tratamiento psicológico de los Servicios Sociales de [...] en el plazo de un mes a contar

${ }^{18}$ Por razones de confidencialidad, se omite cualquier dato identificativo de personas o servicios. 
desde la firma de este acuerdo. A tal efecto, se compromete a aportar a este Servicio de Mediación el certificado de haber acudido a la cita correspondiente y haber comenzado el tratamiento. El Servicio de Mediación Penal enviará periódicamente a la víctima, por correo postal, dicho certificado.

\section{Discusión y conclusiones}

La intervención restaurativa es una intervención de carácter social e innovador. El protagonismo de las personas afectadas por una infracción de índole penal y la recuperación de sus fortalezas para abordar las consecuencias de los hechos permiten satisfacer necesidades concretas de aquéllas.

La innovación en la justicia penal se antoja un movimiento muy contrario a las tendencias sociales y mediáticas actuales, caracterizadas por un crecimiento del uso de la pena privativa de libertad $y$, por extensión, del populismo punitivo ${ }^{19}$. Incluso llegamos a tener propuestas político-criminales de prisión perpetua (Ríos Martín, 2013). Es habitual escuchar la necesidad de ampliar los tipos penales del Código Penal y de aumentar los castigos que establece. Pareciera que no hay otro derecho penal posible, y que las penas, y en especial, la privativa de libertad, son la mejor solución ${ }^{20}$.

Los programas de justicia restaurativa son innovadores desde el momento en que abren la participación al abordaje de conflictos de índole penal a las víctimas y a la propia comunidad, debilitando la fuerza totalizadora del ius puniendi ${ }^{21}$. La percepción de la ciudadanía de participar en algo nuevo y novedoso permite sentirse activo en un proceso donde se va sabiendo lo que ocurre y se

${ }_{19}$ Concepto proveniente de la criminología, atribuido a Antony Bottoms, que "hace alusión a la utilización del Derecho penal por políticos que buscan sacar réditos electorales defendiendo tesis político-criminales como la de que el incremento de las penas conllevarían automáticamente una reducción de las tasas de delito, o el postulado de que las penas refuerzan determinados consensos morales esenciales para la vida en sociedad" (Peres, 2010: 263). En otro sentido, una investigación española sobre la inseguridad ciudadana en las agendas política, pública y mediática, establece que en España, "las reformas penales de 2003 [...] contienen claros elementos de lo que los juristas vienen denominando expansión del Derecho penal, Derecho penal simbólico, neopunitivismo y Derecho penal del enemigo, conceptos todos ellos elaborados a partir de la experiencia internacional" (Zuloaga, 2011: 379).

20 Sobre la ampliación de los castigos, los tipos penales y la creación de la pena de prisión permanente revisable en la reforma del Código Penal de España, aprobado por el Congreso de los Diputados el 21 de enero de 2015 , véase la crítica de un grupo de catedráticos de Derecho Penal de 33 universidades públicas de España. Denuncian que la nueva reforma bebe político-criminalmente de las peores fuentes del siglo XX, de las corrientes más reaccionarias y más autoritarias. Advierten del "claro abandono que se produce del principio de culpabilidad y su sustitución por criterios de peligrosidad: la dignidad humana va a resultar pisoteada en aras de un defensismo a ultranza, y los ciudadanos van a verse entregados no a la seguridad de la norma, sino a la indeterminación de los criterios personales con los que se va a administrar la peligrosidad" (cit. en Álvarez, 2015).

${ }^{21}$ Facultad sancionadora del poder punitivo, hoy día monopolizado por el Estado, con limitada intervención de las víctimas. alcanza una gran satisfacción ${ }^{22}$. Por eso, la justicia restaurativa va más allá de la mera solución del conflicto, pues si se limitara estrictamente a ello, "se estarían ignorando las necesidades e intereses sociales del mantenimiento en la seguridad y la paz social, vitales para la sociedad" (Meier, 1998: 127).

Podemos observar, a la luz de los datos mostrados, que casi un $10 \%$ de los casos han supuesto una conexión directa o indirecta de la intervención restaurativa con la intervención psicosocial que se estuviera haciendo con otros servicios sociales y sociosanitarios. Ello nos recuerda que las transgresiones de las normas nacen en el ámbito social y, por ello, pueden necesitar de un tratamiento e intervención en dicho ámbito (Di Rosa, 2015; Pali, 2014).

Esta conexión nos permitirá aumentar nuestra mirada crítica, evidenciando las relaciones de poder que puedan ser nocivas y dañinas, así como las desigualdades discriminatorias, las dinámicas y las estructuras sociales que crean situaciones de falta de bienestar e injusticia social. La conexión de los procesos restaurativos con servicios sociales y programas de acción psicosocial será un elemento digno de considerar para esta perspectiva. Esta conexión puede ser protocolizada a través de fichas de derivación o puede hacerse de una manera más informal, permitiendo que los servicios sociales, cuando lo necesiten, y las personas implicadas, lo acepten voluntariamente y conozcan el resultado de la intervención restaurativa.

Además, los recursos sociales que puedan ofrecerse desde estos servicios pueden contribuir a mantener la integridad física y psicológica en situaciones de alto riesgo, a través de apoyos instrumentales (ayuda en cuestiones de salud, seguridad física, alimentación) y apoyos emocionales (para dar y recibir afecto). Los recursos sociales son los que contribuyen a mantener el vínculo social y ayudan a la persona que ha sido victimizada a trascender esta situación con apoyos de la comunidad.

Como ejemplo de esta conexión, puede evocarse un proceso restaurativo donde un padre había sido acusado de agredir a su hijo. Los hechos no parecían haber causado un daño muy grave al menor. Conocíamos que el protocolo de análisis de posibles situaciones de riesgo y desamparo a la infancia y adolescencia se pondría en marcha a raíz del atestado elaborado por la Policía Municipal, que trabaja en red con los servicios sociales del municipio. En ese momento, es oportuno coordinarse con esa intervención, establecer un contacto profesional que permita hacer caminar ambas intervenciones paralelamente (sabiendo que responden a diferentes objetivos). De hecho, así fue. El Servicio de Mediación Penal de Barakaldo

${ }^{22}$ En la investigación externa, se destaca que de 539 personas entrevistadas, 432 (el $81,1 \%$ ) repetirían en la mediación y la recomendarían a otras personas (Varona, 2009). 
comunicó al servicio social de base la intervención restaurativa que se ponía en marcha. Se le invitó a participar ${ }^{23}$, lo cual declinó. La trabajadora social del servicio social de base recibió la noticia de esa intervención, y esperó a que terminara para que las personas participantes (madre incluida) acudieran con el resultado restaurativo (acuerdo de reparación al menor) y se pudiera continuar con una intervención acode a la valoración de riesgo del caso.

Los casos analizados que han conllevado colaboración con los servicios sociales han sido, en su totalidad, de intervención familiar, con presencia o no de menores $y$, a veces, de personas mayores, donde ya existía una intervención previa con dichos servicios y las propias partes han optado por llevar a la trabajadora social el resultado del proceso restaurativo.

Hacemos también una observación sobre la conexión con servicios del ámbito de la atención sociosanitaria $\mathrm{y}$, en concreto, de la intervención psiquiátrica. A modo de ejemplo, observamos el caso de una mujer (39 años) que convivía con su madre (79 años) y padre (80 años), el cual solía insultarla y vejarla. El expediente es derivado por un presunto delito de lesiones en violencia doméstica. En la sesión informativa, la víctima explica que se encuentra en tratamiento psiquiátrico desde hace más de diez años en el centro de salud mental de su localidad. El mediador consulta con el psiquiatra la conveniencia de la participación de su paciente en un diálogo reparador con su padre, y obtiene respuesta positiva. Tras el periodo de preparación, y con unos minutos previos al encuentro dialogado con el padre, la víctima acude acompañada por su psiquiatra, con el objetivo de reforzar afectivamente su fortaleza personal de encontrarse con su padre. El encuentro, que finalizó con acuerdo, supuso para la víctima la recuperación de su dignidad, a través de la expresión verbal del daño sufrido por las vejaciones de su padre. De forma paralela, también es reseñable la coordinación con el Servicio de Atención a la Víctima para recabar alguna información concreta que precisaba nuestra víctima protagonista.

En nuestra experiencia, estas conexiones y el trabajo en red con estos servicios en el propio Juzgado de Barakaldo han permitido la atención de necesidades adicionales de las personas participantes - necesidades que excedían aquellas que habían motivado el proceso restaurativo-, y a su vez, la conexión con los servicios sociales para atender necesidades concretas de carácter social.
Los datos también nos ofrecen conexiones con otros servicios adyacentes y complementarios de la administración de Justicia, como los servicios de atención a personas detenidas y los servicios de atención a las víctimas ${ }^{24}$. En el primer caso, la consulta buscaba posibles consecuencias en la ejecución penal. En el caso del Servicio de Atención a la Víctima, se ofrecía orientación e información muy precisa sobre derechos de la víctima.

Desde un análisis con perspectiva de trabajo social, buscamos las similitudes y diferencias entre una intervención de carácter social y una intervención restaurativa. Las similitudes entre los métodos de trabajo social y los de justicia restaurativa se centran en el inicial trabajo de estudio y diagnóstico. Ambas metodologías abogan por la investigación e intervención de, y en, realidades construidas socialmente, que sitúan a personas, familias, grupos y colectivos en situaciones de vulneración de derechos humanos, sociales y de ciudadanía. La diferencia entre ambas estriba en que, en trabajo social, el objeto de la intervención social es la persona en necesidad y en contacto con su medio. En justicia restaurativa, en cambio, el objeto es el hecho delictivo con sus consecuencias (responsabilización y reparación) hacia víctimas, personas ofensoras y otras personas afectadas de la propia comunidad. Ambas metodologías coinciden en la posterior fase de seguimiento y evaluación.

La conexión y colaboración con los servicios sociales, sociosanitarios o de cooperación con la justicia, así como con el tejido social y comunitario, ponen de manifiesto que el abordaje restaurativo de las consecuencias de hechos delictivos requiere de una mirada interdisciplinar, flexible y abierta a la colaboración de otros servicios y programas que puedan atender las necesidades, a veces muy íntimas y otras veces sociales, de las personas protagonistas. De esta manera, podemos superar aquellas intervenciones exclusivamente 'micro' de justicia restaurativa donde sólo participan víctimas y personas victimarias, y avanzar hacia una intervención social que aborde también las desigualdades socioeconómicas estructurales.

Por todo ello, la colaboración de los procesos restaurativos con servicios sociales y programas de acción psicosocial será un elemento imprescindible para un trabajo de carácter integral con las personas ofensoras, víctimas y personas afectadas del tejido comunitario.
23 Siguiendo el modelo neozelandés de conferencias familiares, donde los servicios sociales pueden estar presentes para integrarse en el proceso restaurativo si todas las personas participantes así lo aceptan (MacRae y Zehr, 2004).
${ }^{24}$ En este sentido, y a partir del Real Decreto 1109/2015, de 11 de diciembre, por el que se desarrolla la Ley 4/2015, de 27 de abril, del Estatuto de la Víctima del Delito, y se regulan las Oficinas de Asistencia a las Víctimas del Delito, hay que tener en cuenta el papel que se les da a estas oficinas de informar a las víctimas sobre los servicios de justicia restaurativa. 
ÁLVAREZ, J. (2015): “Catedráticos de 33 universidades denuncian que el código penal 'pisotea la dignidad humana”, Cadena Ser, 2-1-15 [khttp://cadenaser.com/ser/2015/01/21/ tribunales/1421846562_977208.html>, consultado el 21-1-15].

ÁLVAREZ RAMOS, F. (2008): “Mediación penal juvenil y otras soluciones extrajudiciales", International e-Journal of Criminal Sciences, ㄲo 2.

BAZEMORE, G. (2015): “Restorative justice, earned redemption and a communitarian response to crime" [ /http://www.gwu.edu/ ccps/ Bazemore.html, consultado el 13-1-15].

BAZEMORE, G.; y UMBREIT, M. S. (1999): Conferences, Circles, Boards, and Mediations: Restorative Justice and Citizen Involvement in the Response to Youth Crime, Washington DC, US Department of Justice, Office for Juvenile Justice and Delinquency Prevention (BARJ Project).

- (1995): "Rethinking the sanctioning function in juvenilecourt: Retributive or restorative responses to youth crime", Crime \& Delinquency, vol. 41, nํㅜ 3, págs. 296-316.

BERISTAIN, A. (2006): “¿Evolucionamos hacia las antípodas del derecho penal y la criminología? ¿Evolucionamos hacia la justicia victimal?”, Revista Penal, no 17, págs. 34-58.

- (1995): “Aurkezpena/Presentación”, Eguzkilore. Cuaderno del Instituto Vasco de Criminología, $\mathrm{n}-8$, págs. 10-16.

BRAITHWAITE, J. (2003): "The fundamentals of restorative justice”, en DINNEN, S.; JOWITT, A.; y CAIN, T. N. (eds.): A Kind of Mending: Restorative Justice in the Pacific Islands, Canberra, Pandanus Books, págs. 35-43.
CHAPMAN, T.; GELLIN, M.; y ANDERSON, M. (2015): Toolkit for Professionals: Implementing a European Model for Restorative Justice with Children and Young People, Bruselas, International Juvenile Justice Observatory.

CHRISTIE, N. (1984): Los límites del dolor, México, Fondo de Cultura Económica.

CUTRONA, C. (2014): "Community mediation in the United States", en FRITZ, J. M. (ed.): Moving toward a Just Peace. The Mediation Continuum, Cincinnati, Springer, págs. 69-90.

DEPARTAMENTO DE ADMINISTRACIÓN PÚBLICA Y JUSTICIA (2016): Servicio de Mediación Intrajudicial (SMI) (mediación penal). Memoria 2015, Eusko Jaurlaritza-Gobierno Vasco [<http:// www.justizia.net/mediacion-intrajudicial/ texto?id=1290077285652>].

- (2015): Servicio de Mediación Intrajudicial (SMI) (mediación penal). Memoria 2014, Eusko Jaurlaritza-Gobierno Vasco [<http://www. justizia.net/mediacion-intrajudicial/ texto?id=1290077285652>].

DE VICENTE, C. (2007): [“Comunicación”], en Jornada sobre Mediación Penal. La experiencia de Barakaldo, Dirección de Ejecución Penal, Viceconsejería de Justicia, Departamento de Justicia Empleo y Seguridad Social del Gobierno Vasco, págs. 8-13 [khttp://www.jusap.ejgv.euskadi.net/ r47-edukia/es/contenidos/informacion/ mediacion_penal/es_smp/adjuntos/ Jornada\%20Mediaci\%C3\%B3n\%20Penal\%20_ Colegio\%2ode\%20Abogados\%20de\%20 Bizkaia_.pdf〉, consultado el 24-4-14].

DEPARTAMENTO DE JUSTICIA Y ADMINISTRACIÓN PÚBLICA (2011): Protocolo de funcionamiento del servicio de mediación intrajudicial, Eusko Jaurlaritza- 
Gobierno Vasco [<http://www.justizia.net/ mediacion-intrajudicial/documentos〉].

DI ROSA, R. (2015): Mediación, ciudadanía y convivencia entre culturas, Lisboa, Juruá.

DÜNKEL, F.; HORSFIELD, P.; y PĂROŞANU, A. (eds.) (2015): Research and Selection of the Most Effective Juvenile Restorative Justice Practices in Europe: Snapshots from $28 \mathrm{EU}$ Member States, Bruselas, International Juvenile Justice Observatory.

EGLASH, A. (1975): “Beyond restitution: Creative restitution", en HUDSON, J.; y GALAWAY, B. (eds.), Restitution in Criminal Justice: A Critical Assessment of Sanctions, Lexington Books, págs. 91-101.

ESPAÑA (2015a): “Ley Orgánica 1/2015, de 30 de marzo, por la que se modifica la Ley Orgánica 10/1995, de 23 de noviembre, del Código Penal", Boletín Oficial del Estado, no $77,31-3-15$, págs. 27.06127.176 [rhttp://www.boe.es/buscar/doc. php?id=BOE-A-2015-3439>].

- (2015b): "Ley 4/2015, de 27 de abril, del Estatuto de la Víctima del Delito", Boletín Oficial del Estado, no 101, 28-4-15, págs. 36.56936.598 [/http://www.boe.es/buscar/doc. php?id=BOE-A-2015-4606)].

- (2015C): “Ley 41/2015, de 5 de octubre, de modificación de la Ley de Enjuiciamiento Criminal para la agilización de la justicia penal y el fortalecimiento de las garantías procesales", Boletín Oficial del Estado, no 239, 6-10-15, págs. 90.220-90.239 [<http://www.boe.es/ buscar/doc.php?id=BOE-A-2015-10726)].

- (2015d): "Real Decreto 1109/2015, de 11 de diciembre, por el que se desarrolla la Ley $4 / 2015$, de 27 de abril, del Estatuto de la Víctima del Delito, y se regulan las Oficinas de Asistencia a las Víctimas del Delito", Boletín Oficial del Estado, n- 312, 30-12-15, págs. 123.162 123.181 [khttp://www.boe.es/buscar/doc. php?id=BOE-A-2015-14263'].

GUARDIOLA, M. J. et al. (2012): ¿Es el conferencing una herramienta útil para los programas de mediación en el ámbito penal del Departamento de Justicia?, Barcelona, Centro de Estudios Jurídicos y Formación Especializada, Departamento de Justicia de la Generalitat de Cataluña.

HIGHTON, E.; ÁLVAREZ, G.; y GREGORIO, C. (1998): Resolución alternativa de disputas y sistema penal, Buenos Aires, Ad-Hoc.

IGARTUA, I. et al. (2015): Evaluación del coste de la justicia restaurativa integrando indicadores cuantitativos y cualitativos: el caso de la mediación penal aplicada a las infracciones de menor gravedad (Álava, 2013), Vitoria-Gasteiz, Servicio Central de Publicaciones del Gobierno Vasco.

LARSON, J.; y ZEHR, H. (2007): "The ideas of engagement and empowerment”, en JOHNSTONE, G.; y VAN NESS, D., W. (eds.): Handbook of Restorative Justice, Portland, Willan Publishing, págs. 41-58.

MCCOLD, P. (2000): “Overview of mediation, conferencing and circles" [comunicación], 10 ${ }^{\text {th }}$ United Nations
Congress on Crime Prevention and Treatment of Offenders (Viena, 10/17-4-00) [inédito].

MACRAE, A.; y ZEHR, H. (2004): The Little Book of Family Group Conferences. New Zealand Style, Intercourse, Good Books.

MANZANARES, J. L. (2007): Mediación, reparación y conciliación en el Derecho Penal, Granada, Comares.

MARSHALL, T. (1999): Restorative Justice: An Overview, Londres, Home Office. Research Development and Statistics Directorate.

MEIER, B. (1998): "Restorative justice - A new paradigm in criminal law?", European Journal of Crime, Criminal Law and Criminal Justice, vol. 6, nㅜㄹ, págs. 125-139.

MONTES, M. A. (2007): [“Comunicación”], en Jornada sobre Mediación Penal. La experiencia de Barakaldo, Dirección de Ejecución Penal, Viceconsejería de Justicia, Departamento de Justicia, Empleo y Seguridad Social del Gobierno Vasco, págs. 2-7 [khttp://www.jusap.ejgv.euskadi.net/ r47-edukia/es/contenidos/informacion/ mediacion_penal/es_smp/adjuntos/ Jornada\%2oMediaci\%C3\%B3n\%20Penal\%20_ Colegio\%2ode\%2oAbogados\%20de\%20 Bizkaia_.pdf>, consultado el 24-4-14].

NOGUERAS, A.; y GIMENO, R. (2012): “De la 'mediación y la reparación a la víctima' a la 'prevención”, Revista de Educación Social, no 15, págs. 1-15.

NOGUERAS, A.; y GIMENO, R. (coords.). (2015): Tejiendo complicidades. Metodologías de apoyo a la prevención, Departamento de Justicia de la Generalitat de Cataluña, Programa Compartim de Gestión del Conocimiento,

OFICINA DE LAS NACIONES UNIDAS PARA LA DROGA Y EL DELITO (2006): Handbook on Restorative Justice Programmes, Nueva York, Oficina de las Naciones Unidas para la Droga y el Delito.

OLALDE, A. J. (2015): “Estudio multidimensional de algunas prácticas de justicia restaurativa en el País Vasco con lentes de trabajo social (20072012) [tesis doctoral], Universidad de Murcia, Facultad de Trabajo Social.

OLALDE, A. J.; ROMERA, C.; y AGIRRE, A. (2007): “Proyecto de intervención. Servicio de mediación penal reparadora del partido judicial de Barakaldo" [inédito].

ONU (2013): Promoting Restorative Justice for Children, Nueva York, Oficina de las Naciones Unidas.

- (1985): Declaración sobre los Principios Fundamentales de Justicia para las Víctimas de Delitos y del Abuso de Poder, 29-11-85 [/http://www. ohchr.org/SP/Professionallnterest/Pages/ VictimsOfCrimeAndAbuseOfPower.aspx>].

PALI, B. (2014): “Active justice: Restorative justice processes as fertile ground for exercising citizenship", Sistema Penal \& Violência, vol. 6, nํㅜ 1, págs. 31-42.

PARIS, S. (2009): Filosofía de los conflictos. Una teoría para su transformación pacífica, Barcelona, Icaria.

PERES, L. (2010): “Prensa, política criminal y opinión pública: el populismo punitivo en España" [tesis doctoral], Universidad Autónoma de 
Barcelona, Departament de Ciencia Politica i Dret Public.

PETERS, T.; AERTSEN, I. (1995): “Mediación para la reparación: presentación y discusión de un proyecto de investigación-acción”, Eguzkilore. Cuaderno del Instituto Vasco de Criminología, no 8, págs. 129-146.

RÍOS MARTÍN, J. C. (2013): La prisión perpetua en España. Razones de su ilegitimidad ética y de su inconstitucionalidad, Donostia-San Sebastián, Tercera Prensa.

SEGOVIA BERNABÉ, J. L. (2010): “Mediación penal comunitaria y justicia restaurativa. Perspectiva ética y jurídica”, en FUNDACIÓN ÁGAPE (ed.), Mediación penal y penitenciaria. 10 años de camino, Madrid, Arts y Press, págs. 17-56.

SUBIJANA, I. J. (2014): “La mediación penal intrajudicial en la comunidad autónoma del País Vasco: consideraciones a la luz de los datos ofrecidos por la primera memoria elaborada tras la aprobación, en junio de 2011, de la última versión del Protocolo de Funcionamiento del Servicio de Mediación Intrajudicial”, Oñati Socio-Legal Series, vol. 4, nº 3, págs. 351-368.

- (2009): "La justicia a las víctimas del terrorismo", Eguzkilore. Cuaderno del Instituto Vasco de Criminología, nº 23, págs. 79-86.

SUBIJANA, I.; y PORRES, I. (2013): “La viabilidad de la justicia terapéutica, restaurativa y procedimental en nuestro ordenamiento jurídico", Cuadernos Penales Jose María Lidón, nำ 9, págs. 21-58.

TAMARIT, J. M. (2013): “El necesario impulso de la justicia restaurativa tras la Directiva Europea de 2012”, Ars Iuris Salmanticensis. Revista Europea e Iberoamericana de Pensamiento y Análisis de Derecho, Ciencia Política y Criminología, vol. 1, nํㅜ 1, págs. 139-16o.

- (2006): “La justicia reparadora: ¿una justicia para la víctima?”, en BACA, E.; ECHEBURÚA, E.; y TAMARIT, J. M. (eds.): Manual de victimología, Valencia, Tirant lo Blanch, págs. 439-462.

UMBREIT, M. S. et al. (2005): "Restorative justice in the twenty-first century: A social movement full of opportunities and pitfalls", Marquette Law Review, vol. 89, págs. 250-304.

UNIÓN EUROPEA (2012): “Directiva 2012/29/UE del Parlamento Europeo y del Consejo, de 25 de octubre de 2012, por la que se establecen normas mínimas sobre los derechos, el apoyo y la protección de las víctimas de delitos, y por la que se sustituye la Decisión marco 2001/220/ JAl del Consejo", Diario Oficial de la Unión Europea, L 315, págs. 57-73 [<http://eur-lex. europa.eu/legal-content/ES/NOT/?uri=CELEX:3 2012Lo029\&qid=1461526661505〉].

VANFRAECHEM, I. (2003): “Evaluating conferencing for serious juvenile delinquents" [comunicación], $6^{\text {th }}$ International Conference on Restorative Justice (5/8-11-03, Vancouver) [inédito]

VAN NESS, D. W.; y STRONG, K. H. (2010): Restoring Justice: An Introduction to Restorative Justice, $4^{-}$ed., Cincinnati, Anderson Publishing.

VAN WORMER, K. (2008): Restorative Justice across the East and the West, Taoyuan, Casa Verde Publishing.

VARONA, G. (2009): Justicia restaurativa a través de los servicios de mediación penal en Euskadi. Evaluación externa de su actividad (octubre 2008-septiembre 2009) [<http://www.ehu.es/ documents/1736829/2153076/Justicia+restaur ativa+a+traves+de+los+servicios+de+mediacio $n+$ penal.pdf>, consultado el 23-9-14].

- (2008): Evaluación externa de la actividad del Servicio de Mediación Penal de Barakaldo (julio-diciembre de 2007) [<http://www.jusap.ejgv.euskadi. net/r47-edukia/es/contenidos/informacion/ mediacion_penal/es_smp/adjuntos/IVACKREI Evaluación 2007 SMP Barakaldo.2.pdf〉, consultado el 29-4-14].

VARONA, G.; IGARTUA, I.; y OLALDE, A. J. (2011): “Hacia una teoría de la justicia restaurativa desde la investigación acción: ¿cómo evaluar el beneficio social del derecho al encuentro de personas víctimas y victimarias?" [póster], VIII Congreso de la Sociedad Española de Investigación Criminológica (Donostia-San Sebastián, 29-6/1-12-11) [<http://www.ivac. ehu.es/p278-content/es/contenidos/evento/ ivckei_actividades/es_activida/adjuntos/ PosterVarona-Igartua-Olalde.pdf〉, consultado el 15-11-11].

WALKER, L. (2015): “Albert Eglash \& the history of restorative justice" [entrada en blog], en WALKER, L., Restorative Justice \& Other Public Health Approaches for Healing. Transforming Conflict into Resiliency [<http://www. lorennwalker.com/blog/?p=117〉, consultado el 13-1-15].

WEXLER, D. B.; y WINICK, B. J. (1996): Law in a Therapeutic Key: Developments in Therapeutic Jurisprudence, Durham, Carolina Academic Press.

WRIGHT, M. (1991): Justice for Victims and Offenders, Philadelphia, Open University Press.

ZINSSTAG, E.; TEUNKENS, M.; y PALI, B. (2011): Conferencing: A Way forward for Restorative Justice in Europe, Lovaina, European Forum for Restorative Justice.

ZEHR, H. (2011): Justícia restauradora. principis i pràctiques, Barcelona, Icaria.

- (2002): The Little Book of Restorative Justice, Intercourse, Good Books.

ZULOAGA, L. (2011): “La priorización de la inseguridad ciudadana como problema. Las claves de su presencia en la agenda pública" [tesis doctoral], Universidad Pública de Navarra. 